\section{Association Alzheimer}

Suisse: nouvelle brochure

Les patients en état de
confusion ou atteints de
démence à l'hôpital
Informations pour
les familles et les amis

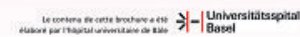

«Les patients en état de confusion ou atteints de démence à l'hôpital» s'appelle la nouvelle brochure de l'Association Alzheimer Suisse, élaborée en collaboration avec l'hôpital universitaire de Bâle, à l'attention des familles et amis. La brochure peut être commandée chez ou téléchargée sur www.alz.ch.

(Association Alzheimer Suisse)

\section{Berner Fachhochschule} beantragt Masterstudiengänge in Pflege und Physiotherapie

Die Berner Fachhochschule will ihr Angebot um konsekutive Masterstudiengänge in Pflege und Physiotherapie erweitern und beantragt deren Durchführung beim Regierungsrat des Kantons Bern. Die Genehmigung vorausgesetzt, starten die Studiengänge im Herbst 2010.

(www.gesundheit.bfh.ch)

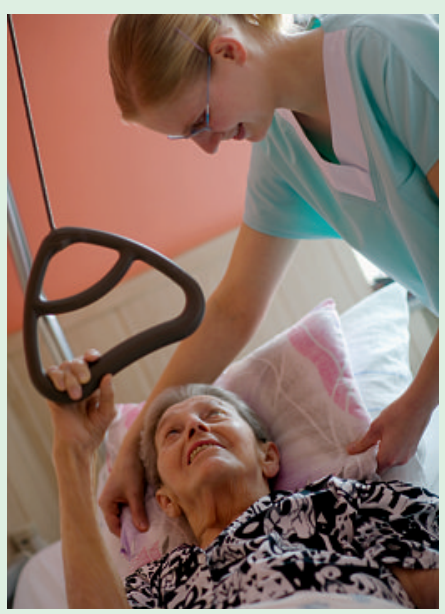

\section{Accord de coopération scientifique et technologique entre la Suisse et les Etats-Unis}

Le secrétaire d'Etat Mauro Dell'Ambrogio et le directeur de la National Science Foundation, l'agence fédérale américaine de promotion de la recherche, Arden Bement, ont signé un accord bilatéral de coopération scientifique et technologique entre les deux pays. La NSF joue un rôle de premier plan dans les bonnes relations améri-

cano-suisses en matière de coopération universitaire et de recherche: il finance des bourses pour les chercheurs suisses se rendant aux Etats-Unis et soutient des projets de recherche.

\section{(Secrétariat d'Etat à l'éducation} et à la recherche SER)

\section{Suchtprävention beim Alkoholverkauf}

Seit März 2008 begleitet die Suchtprävention Aargau 42 Gemeinden bei der Planung von Testkäufen. Ziel ist es, die Alkoholverkaufsstellen vor Ort für die Umsetzung des Jugendschutzgesetzes zu sensibilisieren und zu gewinnen. Die Resultate lassen jedoch eine positive Prognose $\mathrm{zu}$, da die meisten Betriebe sehr motiviert und engagiert sind. Allgemein stellen wir fest, dass eine hohe Akzeptanz gegenüber den Testkäufen besteht und von den Beteiligten der Schutz der Jugendlichen als Grundwert anerkannt wird.

\section{(Suchtprävention Aargau)}

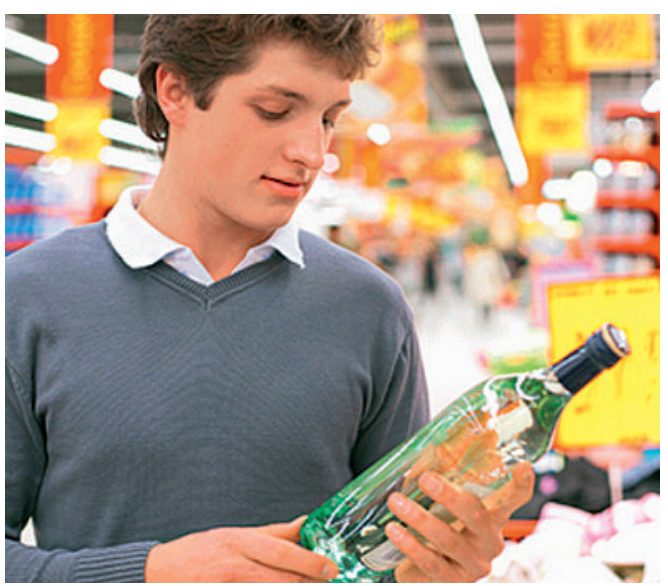

In Alkoholverkaufsstellen des Kantons Aargau finden Testkäufe statt.

\section{Herzpatienten: Unterstützung für Ärzte}

Die ambulante Betreuung von Herzinsuffizienzpatienten ist eine Herausforderung. Mit einer neuen Dienstleistung bietet die Schweizerische Herzstiftung ab 1. April 2009 Unterstützung an: Ärztinnen und Ärzte können für die ambulante Schulung und Beratung ihrer Patienten eine ausgebildete Herzinsuffizienzberaterin beiziehen.

Ziele sind eine bessere Lebensqualität für die Betroffenen und weniger Spitaleinweisungen. Vorerst richtet sich das Angebot an die Ärzteschaft in den Kantonen Basel-Stadt und Baselland.

\section{(Schweizerische Herzstiftung)}

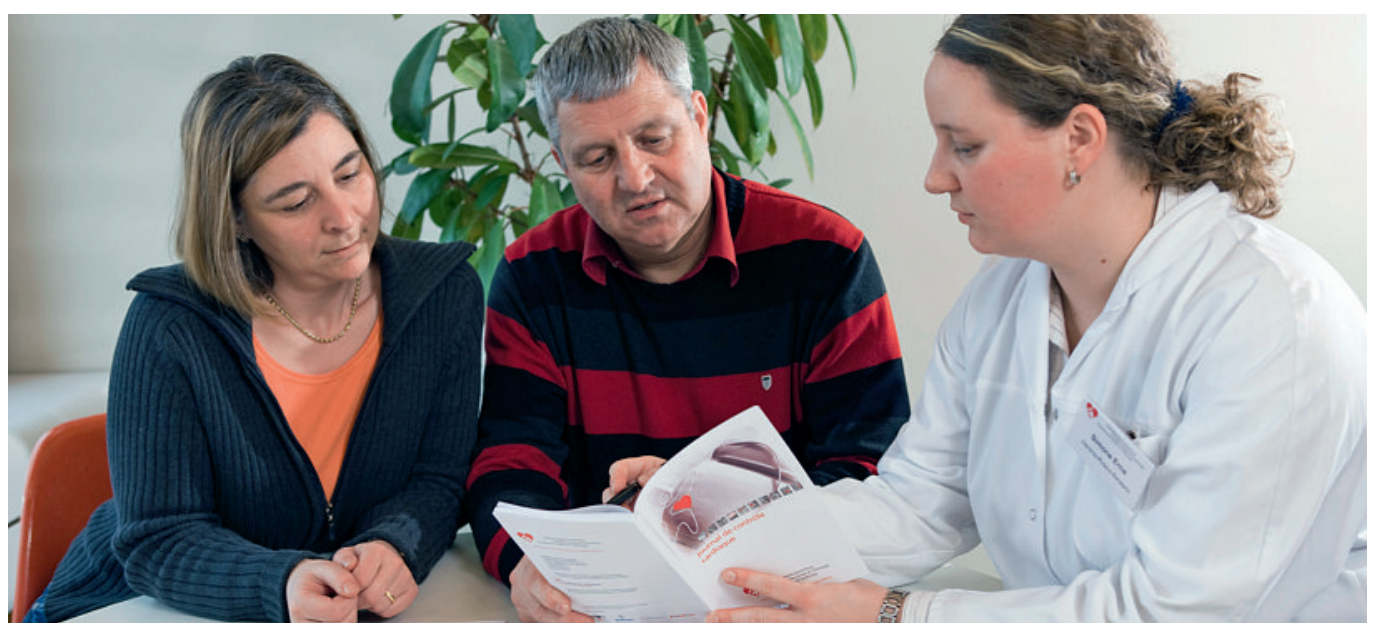

Patienten und ihre Angehörigen erfahren in der Herzinsuffizienzberatung, worauf sie bei ihrer Erkrankung besonders achten müssen. 